\title{
Natural Reinfection with Respiratory Syncytial Virus Does Not Boost Virus-Specific T-Cell Immunity
}

\author{
LOUIS BONT, JORIEN VERSTEEGH, WENDY T.N. SWELSEN, COBI J. HEIJNEN, \\ ANNEMIEKE KAVELAARS, FRANK BRUS, JOS M.TH. DRAAISMA, \\ MARTHA PEKELHARING-BERGHUIS, RONNIE A.A.M. vAN DIEMEN-STEENVOORDE, \\ AND JAN L.L. KIMPEN \\ Wilhelmina Children's Hospital, University Medical Center, Utrecht, The Netherlands [L.B., J.V., \\ W.T.N.S., C.J.H., A.K., J.L.L.K.]; Department of Pediatrics, Rijnstate Hospital, Arnhem, The Netherlands \\ [F.B.]; Department of Pediatrics, St. Elisabeth Hospital, Tilburg, The Netherlands [J.M.Th.D.]; \\ Department of Pediatrics, Diakonessen Hospital, Utrecht, The Netherlands [M.P.B.]; Department of \\ Pediatrics, St. Antonius Hospital, Nieuwegein, The Netherlands [R.A.A.M.v.D.-S.]
}

\begin{abstract}
ABST
To determine the role of respiratory syncytial virus (RSV)-
specific cell-mediated immunity during natural reinfection, we in-
vestigated whether RSV-specific T-cell responses protect against
reinfection and, subsequently, whether reinfection boosts virus-
specific memory. In a cohort of 55 infants who were hospitalized for
RSV bronchiolitis, RSV-specific lymphoproliferative responses in
the peripheral blood were measured at three time-points: on admis-
sion, 4 wk after admission, and 1 y later, after the second winter
season. Memory was defined as a stimulation index (SI) $>2$. During
the second winter season, nasal secretions were collected in every
case of a runny nose. Reinfection was diagnosed if immunofluores-
cence or PCR was positive for RSV. Virus-specific memory was
found in one child on admission for primary RSV infection, whereas
4 wk later 44 infants ( $80 \%$ ) had memory. Reinfection with RSV was
found in 23 infants (43\%) during the second winter season. After the
second season, memory was found in 20 infants (38\%). No differ-
ences in SI after the second winter season were found between
\end{abstract}
RSV is one of the most important respiratory pathogens in infancy causing the majority of lower respiratory tract infections during the winter season. Hospitalization rates for RSV illness are $1-30$ cases per 1000 infants $<1$ y of age (1-3). In hospitalized infants with RSV bronchiolitis, mechanical ventilation is required in $7-21 \%$ of cases (4-6). Mortality in RSV-infected infants with lower respiratory tract symptoms is $<1 \%$ (7).

Reinfection with RSV occurs frequently and usually has a mild character with symptoms of uncomplicated upper respi-

Received May 10, 2001; accepted November 11, 2001.

Correspondence: J.L.L. Kimpen, Department of Pediatric Infectious Diseases, Wilhelmina Children's Hospital, University Medical Center, POB 85090, 3508 AB Utrecht, The Netherlands; e-mail: j.kimpen@wkz.azu.nl

Supported by the Dutch Asthma Foundation (grant number 32.96.08).

DOI: 10.1203/01.PDR.0000028458.76706.C7 infants with and without reinfection (2.3 versus 2.1). However, a highly significant correlation was found between SI measured $4 \mathrm{wk}$ after primary RSV infection and SI after the second winter season $(r$ $=0.40, p=0.001)$. In conclusion, $\mathrm{RSV}$-specific T-cell responses did not provide protection against reinfection. Moreover, reinfection did not boost RSV-specific T-cell proliferation. To explain both findings, it is hypothesized that RSV-specific T cells fail to expand in vivo upon reinfection. (Pediatr Res 52: 363-367, 2002)

\section{Abbreviations}

RSV, respiratory syncytial virus

CMI, cell-mediated immunity

RT-PCR, reverse transcriptase PCR

TCID, tissue culture infection dose

LPR, lymphoproliferative response

IFN, interferon ratory tract infection (8). Neutralizing antibodies induced by primary RSV infection appear to provide only partial protection for a limited period of time, which does probably not last until the subsequent RSV season $(8,9)$. Evidence that intact cell-mediated responses play a role in clearance of the virus and protection against reinfection was derived from animal studies (10). In humans, little information is available on the role of virus-specific CMI induced during primary infection in the protection against reinfection with RSV.

Currently, no vaccine for RSV is available. In the 1960s, a formalin-inactivated vaccine was used in infants (11). No protection against naturally acquired RSV was observed. In contrast, enhanced disease and increased mortality were observed during RSV infection after vaccination. CMI has been implicated in the pathogenesis of this phenomenon (12). Several strategies for safe 
and effective vaccination, including immunization with attenuated strains and subunit vaccines are under investigation at the moment (13-16). The immune response to an RSV vaccine should be protective, persistent, and not disease-enhancing upon subsequent contact with the virus. Similar to other vaccine strategies, such as measles and pertussis, it is conceivable that boosting is required to maintain virus-specific CMI. For this reason, it is important to study the characteristics of the memory response in relation to recurrent infection.

In this prospective follow-up study, we investigated the development over time of RSV-specific T-cell responses in a cohort of infants hospitalized for RSV bronchiolitis. The first aim of the study was to determine whether RSV-specific T-cell responses induced during primary RSV bronchiolitis protect against reinfection during the subsequent epidemic. The second aim of the study was to investigate whether virus-specific $\mathrm{T}$-cell responses acquired during primary infection are boosted by natural reinfection with RSV.

\section{METHODS}

Study population. Infants were included during one winter epidemic in five hospitals in the Netherlands. Inclusion criteria were as follows: hospital admission, lower respiratory tract symptoms, age $<13 \mathrm{mo}$, and positive immunofluorescence for RSV infection of epithelial cells in nasopharyngeal secretions. Lower respiratory tract symptoms were severe chest cough, wheezing, hoarseness, stridor, and shortness of breath (17), as well as cyanosis and apnea. Prematurely born infants with chronic lung disease and infants with wheezing illness before RSV bronchiolitis were not included. The study was approved by the medical ethical committees in all participating centers. Parents of subjects gave written informed consent.

Documentation of reinfection. During the second winter season, the occurrence of reinfection was studied. Parents received written and oral information during a home visit during the fall season before this part of this study. During the winter season, parents contacted the investigators (J.V.) in case of respiratory symptoms. To ascertain cooperation by parents, a telephone call was made every $3 \mathrm{wk}$. Within $48 \mathrm{~h}$ after onset of respiratory symptoms, home visits were made to perform nasal washes. No physical examination was performed.

RSV reinfection was confirmed by a commercially available direct immunofluorescence assay using FITC-labeled MAb (IMAGEN, DAKO, Glostrup, Denmark) and by RT-PCR. Reinfection was defined as a positive immunofluorescence or PCR on nasal washings.

$\boldsymbol{R T}$-PCR. RNA extraction was performed according to the method described by Boom et al. (18). Briefly, 10-100 $\mu \mathrm{L}$ respiratory specimen was mixed with $900 \mu \mathrm{L}$ lysis buffer and $50 \mu \mathrm{L}$ silica and incubated for $10 \mathrm{~min}$ at room temperature to bind the nucleic acid to the silica particles. Unbound material was then removed by several washing steps. The RNA was subsequently eluted in $100 \mu \mathrm{L} 40 \mathrm{ng} / \mu \mathrm{L}$ polyA RNA before performing a one-tube RT-PCR.

After viral RNA isolation, an equivalent of $1-10 \mu \mathrm{L}$ of respiratory specimen was used to reverse transcribe and amplify the NP gene. A one-tube RT-PCR was performed essen- tially as described by Nijhuis et al. (19) using $1.5 \mathrm{mM} \mathrm{MgCl}_{2}$, $0.4 \mu \mathrm{M}$ of primer RS-1 [5'-GGA TTG TTT ATG AAT GCC TAT GGT-3' (Amersham Pharmacia Biotech)] and primer RS-2 (5'-TTC TTC TGC TGT YAA GTC TAR TAC AC-3'). The amount of amplified product was increased further in a nested amplification.

Five microliters of first PCR product is further amplified in a nested amplification, essentially as described by Nijhuis et al. (19), using $4.5 \mathrm{mM}$ of $\mathrm{MgCl}_{2}$ and $0.4 \mu \mathrm{M}$ of primer RS-3 (5'GGA TTC TAC CAT ATA TTG AAC AA-3') and primer RS-4 (5'-CTR TAC TCT CCC ATT ATG CCT AG-3').

Five microliters of nested PCR products were visualized on an ethidium bromide-stained agarose gel using UV illumination. A 100-bp marker was used to control fragment lengths.

Virus preparation. Long-strain RSV was cultured in Hep-2 cells (courtesy of Dr. A.M. van Loon, Department of Virology, University Medical Center, Utrecht, The Netherlands) and 1:1 diluted in sucrose-gelatine solution Z7725a (Laboratory of Vaccine Research, National Institute of Public Health and Environment, Bilthoven, The Netherlands). Titers were determined in Hep-2 cells using the TCID50 method described by Karber (20) (TCID50 $\left.2 \times 10^{5}\right)$. A control antigen was prepared in a similar fashion from uninfected Hep-2 cultures. Virus and control antigen were each prepared as one batch. Virus and control antigen were stored in aliquots at $-80^{\circ} \mathrm{C}$.

$\boldsymbol{R S V}$-specific T-cell responses. RSV-specific LPR were performed using a whole blood culture assay as described previously $(21,22)$.

At three time points, heparinized blood was taken from subjects for whole blood cultures. The first blood sample was taken within $24 \mathrm{~h}$ after admission $(\mathrm{t}=1)$. In only two of five participating hospitals a blood sample was taken at this time point. The second blood sample was taken 3-4 wk after the initial admission $(t=2)$. The third sample was taken immediately after the second RSV epidemic $(t=3)$. At $t=3$, RSV-specific LPR, but no cytokine profiles, were determined.

Freshly taken heparinized blood was diluted 1:10 in RPMI 1640 medium (Invitrogen, Carlsbad, CA) and aliquoted (150 $\mu \mathrm{L})$ into 96-well culture plates (NUNC A/S, Roskilde, Denmark). Whole blood was infected with RSV at a multiplicity of infection of $0.1-1.0$ or control suspension. Cultures were incubated for $6 \mathrm{~d}$ at $37^{\circ} \mathrm{C}$ in $5 \% \mathrm{CO}_{2}$. Forty-eight hours after infection, pooled supernatants were collected for cytokine measurement. Five days after infection, lymphocytes were pulsed with $0.25 \mu \mathrm{Ci}{ }^{3} \mathrm{H}-$ thymidine for $18 \mathrm{~h}$ and thymidine incorporation was expressed as counts per minute (LPR). Stimulation index was defined as the ratio between LPR in cultures stimulated with RSV and control antigen. A memory response was defined as a stimulation index $\geq 2.0$. All cultures were performed in quadruplicate. All cultures were performed in the same laboratory. Pooled supernatants were kept at $-80^{\circ} \mathrm{C}$.

Cytokine assays. Cytokines that were measured in supernatants of RSV-stimulated whole blood cultures were IL-4, IL10 , IL-12, and IFN- $\gamma$. Concentrations of IL-4, IL-10, and IFN- $\gamma$ were determined using ELISA kits supplied by the Dutch Laboratory for Blood Transfusion (CLB, Amsterdam, The Netherlands). The detection limit of the assay for IL-4 was $2 \mathrm{pg} / \mathrm{mL}$, for IL-10 $2.5 \mathrm{pg} / \mathrm{mL}$, and for IFN- $\gamma 4 \mathrm{pg} / \mathrm{mL}$. 
Concentrations of IL-12 were determined using ELISA kits from R \& D Systems Europe (Oxford, UK); the detection limit was $7.8 \mathrm{pg} / \mathrm{mL}$. When cytokine values were not detectable, the minimum detectable level was used for statistical analysis.

Statistical analysis. Cytokine production and stimulation indices in RSV-stimulated cultures were logarithmically transformed and expressed as geometric mean and $95 \%$ confidence interval (CI). All tests of significance were two sided. Pearson correlation coefficient was used to describe the correlation between LPR at $t=2$ and $t=3$. Spearman's correlation coefficient was used to analyze the correlation between RSVspecific LPR or cytokine responses and age. Paired $t$ test was used to analyze differences in (log-transformed) values between different time points. Unpaired $t$ test was used to analyze differences in (log-transformed) values between infants with and without reinfection. All tests of significance were 2-sided. A $p$ value $<0.05$ was considered statistically significant.

\section{RESULTS}

Subject characteristics. The investigated population consisted of 55 patients. Thirty patients (55\%) were boys, median age at the time of RSV bronchiolitis was $7 \mathrm{wk}$. Ten infants $(18 \%)$ were born prematurely (range 29-36 wk). Ten infants (18\%) needed mechanical ventilation. One child had cardiac disease, none of the children had immunodeficiency. None of the prematurely born infants had received RSV prophylaxis. None of the patients received ribavirin or systemic anti-inflammatory agents, including corticosteroids. Patients did not receive inhaled corticosteroids during RSV bronchiolitis. All patients survived.

$\boldsymbol{R S V}$-specific $T$-cell responses. A pilot study was performed in samples taken on admission and 3-4 wk after primary RSV infection to determine kinetics of LPR and cytokine responses. At $\mathrm{t}=2$, maximum LPR to RSV were found after $5 \mathrm{~d}$ of culture. Maximum IL-10 production was found at $48 \mathrm{~h}$. The pattern and magnitude of IL-10 responses at $t=1$ and $t=2$ were comparable and unrelated to stimulation indices. Maximum IFN- $\gamma$ production at $\mathrm{t}=1$ and $\mathrm{t}=2$ was found after $48 \mathrm{~h}$ and $120 \mathrm{~h}$, respectively. IFN- $\gamma$ and IL-10 responses in control antigen-stimulated cultures were undetectable or relatively low at any time point compared with RSV-stimulated cultures. IL-4 production in RSV-stimulated cultures remained low $(<10$ $\mathrm{pg} / \mathrm{mL}$ ) and was not higher than IL-4 production in cultures stimulated with control antigen. IL-12 production was not detectable at either $\mathrm{t}=1$ or $\mathrm{t}=2$. We therefore concluded there is no RSV-specific IL-4 or IL-12 production under these culture conditions (data not shown).

At $\mathrm{t}=1$, during the acute phase of RSV bronchiolitis, whole blood cultures were performed in 22 infants. In RSVstimulated whole blood cultures at $\mathrm{t}=1$, only one patient $(4.5 \%)$ had a memory response suggesting earlier infection. RSV-induced IFN- $\gamma$ and IL-10 responses at $\mathrm{t}=1$ were 13 (95\% CI: 4-199) and 25.7 (95\% CI: 12.5-52.7) $\mathrm{pg} / \mathrm{mL}$, respectively. IFN- $\gamma$ levels were below detection level in $45 \%$ and $0 \%$ of cases at $t=1$ and $t=2$, respectively. Il- 10 could be measured in all cases at $t=1$ and $t=2$.

At $\mathrm{t}=2$, during the convalescent phase of RSV bronchiolitis, whole blood cultures were performed in 55 infants. Forty- four patients $(80 \%)$ had a memory response at $t=2$, the stimulation index was 5.1(95\% CI: 3.7-8.4). RSV-induced IFN- $\gamma$ production at $\mathrm{t}=2$ was $60(95 \%$ CI: $48-79) \mathrm{pg} / \mathrm{mL}$, significantly higher than at $\mathrm{t}=1(p<0.01)$. RSV-induced IFN- $\gamma$ production at $\mathrm{t}-2$ was highly correlated with the RSVspecific LPR at t-2 $(r=0.80, p<0.001)$. RSV-induced IL-10 production at $\mathrm{t}=2$ was $16(95 \%$ CI: $11-23) \mathrm{pg} / \mathrm{mL}$, not significantly different from $t=1$. At $t=2$, no significant correlation was found between age and RSV-specific LPR or cytokine responses. Mechanically ventilated infants had higher LPR than nonventilated infants ( 8.5 and 3.9, respectively, $p=$ 0.02 ), which is in line previous reports (22).

At $\mathrm{t}=3$, after the second winter season, RSV-specific lymphoproliferation was measured in 53 infants. No blood was drawn in two infants $(4 \%)$. A memory response was found in 20 infants (38\%). RSV-specific LPR was significantly lower than after the primary RSV infection (stimulation index $=2.2$ versus 5.1, $p<0.001)$. RSV-specific LPR at $\mathrm{t}=2$ and $\mathrm{t}=3$ were highly correlated $(r=0.40, p=0.001)$ (Fig. 1).

Reinfection during second winter season. Eighty-five episodes of respiratory tract symptoms were reported, and reinfection with RSV was diagnosed in 23 infants (42\%). In all 23 cases PCR was positive, whereas immunofluorescence was positive in only 9 of 23 cases of RSV infection (39\%).

RSV-specific cellular immune responses at $\mathrm{t}=2$ was compared between infants with and without reinfection to assess whether RSV-specific T-cell responses protected against reinfection. No differences in LPR were found between infants with and without reinfection (Fig. 2A). In addition, infants with and without reinfection had comparable RSV-specific IFN- $\gamma$ (70 versus $54 \mathrm{pg} / \mathrm{mL}$ ) and IL-10 production (13 versus 16 $\mathrm{pg} / \mathrm{mL})$ at $\mathrm{t}=2$.

$\mathrm{RSV}$-specific LPR at $\mathrm{t}=3$ was compared between infants with and without reinfection to assess whether RSV-specific T-cell proliferation was boosted by reinfection. No differences in LPR at

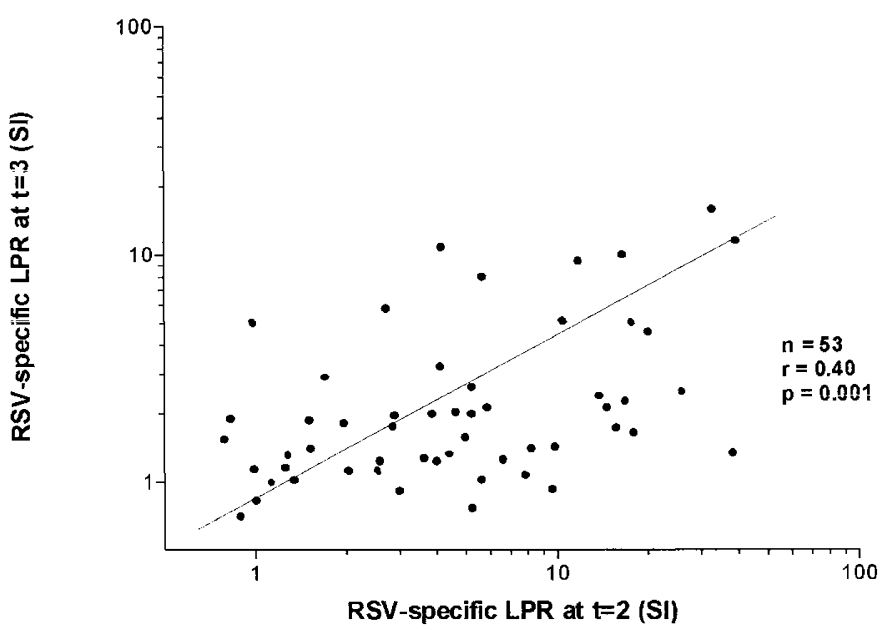

Figure 1. Correlation between RSV-specific lymphoproliferative responses during primary RSV infection and after the subsequent winter season. RSVspecific lymphoproliferative responses [stimulation index $(S I)$ ] were measured 3-4 wk after hospitalization for RSV bronchiolitis $(\mathrm{t}=2)$ and after the subsequent winter season $(t=3)$. Lymphoproliferative responses were determined by thymidine incorporation in whole blood cultures stimulated with RSV for $5 \mathrm{~d}$. Pearson's correlation coefficient is shown. 
$\mathrm{t}=3$ were found between infants with and without reinfection (2.1 and 2.3, respectively) (Fig. 2B). The correlation between LPR at $\mathrm{t}=2$ and $\mathrm{t}=3$ was separately analyzed for infants with and without reinfection. In infants with and without reinfection, the correlation between LPR at $\mathrm{t}=2$ and $\mathrm{t}=3$ was similar $(r=0.41$, $p<0.05$ and $r=0.40, p<0.05$, respectively).

\section{DISCUSSION}

The results of this study show that virus-specific T-cell responses induced during primary RSV infection do not protect completely against subsequent reinfection. In addition, reinfection with RSV did not boost RSV-specific LPR.

Reinfections with RSV occur throughout life (23), implying that immunity induced by natural infection provides little longterm protection against reinfection. Naturally induced and exogenously administered RSV-specific antibodies provide incomplete protection, which is of short duration $(9,24-26)$. To date, sparse
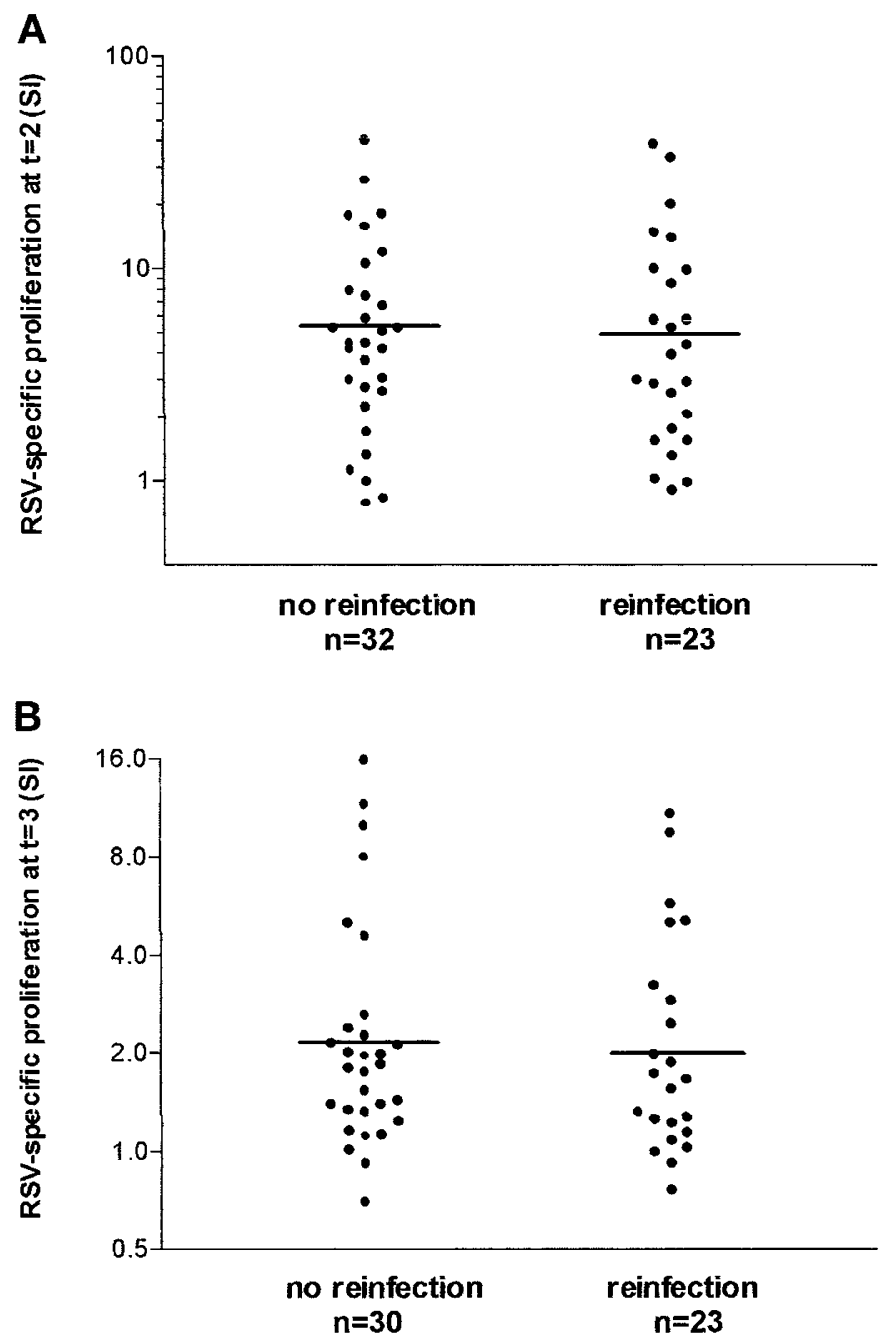

Figure 2. RSV-specific lymphoproliferative responses in infants with and without reinfection with RSV. RSV-specific lymphoproliferative responses [stimulation index $(S I)$ ] were measured 3-4 wk after hospitalization for RSV bronchiolitis $(\mathrm{t}=2)(A)$ and after the second winter season $(\mathrm{t}=3)(B)$ in infants with and without reinfection with RSV. Lymphoproliferative responses were determined by thymidine incorporation in whole blood cultures stimulated with RSV for $5 \mathrm{~d}$. Geometric means are shown. data exist on the protection against reinfection provided by naturally acquired CMI $(24,27)$. In a follow-up study from the early 1980s, no relationship was found between RSV-specific lymphoproliferative responses induced during primary infection and the risk for subsequent culture-proven reinfection (24). However, it can be doubted whether the sensitivity of viral cultures in this study was suitable to diagnose (usually mild) reinfection (28). Assuming positive PCR for RSV indicates RSV infection, the present study shows that the sensitivity of immunofluorescence for RSV infection in this patient group was only 39\%. Thus, PCR, and not culture or immunofluorescence, is required to adequately establish mild reinfection with RSV.

One of the limitations of the present study is that we did not attempt to measure the degree of respiratory disease. Therefore, we cannot exclude that RSV-specific cell-mediated responses decrease the severity of disease in case of reinfection. In addition, in the present study, RSV-specific CMI is represented by virus-specific LPR. Although this is in line with previous studies $(22,27)$, it is not known what part of CMI is reflected by RSV-specific LPR. The assay measures proliferation in a pool of heterogeneous cells. Therefore, LPR may reflect proliferation of cytotoxic $\mathrm{T}$ cells (CTL), cytokineproducing cells, or nonspecific cells that respond to IL-2 produced in the culture system. Cytotoxicity assays measure $\mathrm{CTL}$ responses by $\mathrm{CD}^{+}$cells and reflect a more accurate effector function of CMI. However, little data are available on CTL responses in infants during RSV infection $(29,30)$.

To address the role of RSV-specific CTL in protection against infection in the mouse model, vaccination studies with vaccinia virus expressing the M2 protein of RSV were performed. It was shown that protection against RSV infection largely depended on CTL formation (31). CTL responses waned within $45 \mathrm{~d}$ after vaccination, which was paralleled by a loss in protection.

In the present study, RSV-specific LPR was induced by primary RSV infection in the majority of infants, which is in line with previous studies (22). Memory was found in one child during the acute phase of disease, whereas 3-4 wk later memory to RSV was found in $80 \%$ of the infants. To our surprise, we did not find evidence that reinfection boosted virus-specific CMI, inasmuch as infants with and without reinfection had similar RSV-specific $\mathrm{LPR}$ at $\mathrm{t}=2$ and $\mathrm{t}=3$. Moreover, RSV-specific LPR at $\mathrm{t}=2$ and $\mathrm{t}=3$ were highly correlated. Therefore, it can be concluded that RSV-specific LPR induced during primary RSV bronchiolitis partially persists for more than a year and is not boosted by naturally acquired reinfection.

The physiologic role of RSV-specific T cells during reinfection is not well understood. Firstly, RSV-specific T-cell responses did not protect against reinfection. Secondly, virusspecific LPR were induced by primary RSV infection, but not boosted by reinfection. Both findings may be explained by an absence of in vivo expansion of RSV-specific T cells during a re-encounter with RSV. It is uncertain, however, why RSVspecific memory $\mathrm{T}$ cells are formed during primary infection, but do not proliferate in vivo during reinfection.

The immune response during reinfection with RSV is apparently effective, inasmuch as symptoms are usually mild and last for a short period. If RSV-specific T cells do indeed fail to expand in vivo during reinfection, it can be questioned whether 
T-cell memory plays a major role in the immune response during reinfection. B-cell memory may be more important during reinfection. This is supported by a prominent rise in neutralizing antibodies observed after reinfection with RSV (8). In addition, nonadaptive immunity could have a function in the elimination of RSV during reinfection. Natural killer (NK) cells are important in the defense against viruses because they are capable of providing cytotoxicity and producing cytokines, including IFN- $\gamma(32)$. Although no data exist on the role of NK cells during RSV infection in humans, this cell type has been implicated in the immune response during RSV infection in mice $(33,34)$. In addition, type I interferons (IFN- $\alpha / \beta)$ could play a role in the antiviral immune response. These cytokines with direct antiviral properties are produced in high amounts by airway epithelium upon infection with RSV (35) and they are found in the airways of RSV-infected infants (36).

An important aim in the development of a vaccine against viruses is the induction of virus-specific memory. Subsequent encounter with the virus should result in expansion of at least part the pool of memory $\mathrm{T}$ cells. The present study clearly shows that RSV-specific T cells do not necessarily expand during reinfection. If a future RSV vaccine for humans induces RSV-specific T cells, which lack the potential to expand in vivo upon natural infection, this could have implications for the effectiveness of the vaccine. Limited protection by memory $\mathrm{T}$ cells would be expected, and the effect of the vaccine would then largely depend on the formation of B-cell memory. It remains to be seen whether B-cell memory is sufficient for protection against reinfection.

In conclusion, the present study shows that RSV-specific T-cell responses do not protect against reinfection. Moreover, reinfection does not boost RSV-specific LPR. Together, these findings suggest that RSV-specific T cells do not expand in vivo upon reinfection with RSV, which could bear relevance for the development of an effective vaccine.

Acknowledgments. The authors thank Dr. A.M. van Loon (University Medical Center, Utrecht, The Netherlands) for providing facilities to prepare RSV. We also thank Mrs. J. Zijlstra and Mrs. M. Ringeling-Van der Pol (University Medical Center, Utrecht, The Netherlands) for excellent technical assistance.

\section{REFERENCES}

1. Karron RA, Singleton RJ, Bulkow L, Parkinson A, Kruse D, DeSmet I, Indorf C, Petersen KM, Leombruno D, Hurlburt D, Santosham M, Harrison LH 1999 Severe respiratory syncytial virus disease in Alaska native children. RSV Alaska Study Group. J Infect Dis 180:41-49

2. Shay DK, Holman RC, Newman RD, Liu LL, Stout JW, Anderson LJ 1999 Bronchiolitis-associated hospitalizations among US children, 1980-1996. JAMA 282:1440-1446

3. Wang EEL, Law BJ 1998 Respiratory syncytial virus infection in pediatric patients. Semin Pediatr Infect Dis 9:146-153

4. Outwater KM, Crone RK 1984 Management of respiratory failure in infants with acute viral bronchiolitis. Am J Dis Child 138:1071-1075

5. Frankel LR, Lewiston NJ, Smith DW, Stevenson DK 1986 Clinical observations on mechanical ventilation for respiratory failure in bronchiolitis. Pediatr Pulmonol 2:307-311

6. Tissing WJE, Van Steensel-Moll HA, Offringa M 1993 Risk factors for mechanical ventilation in respiratory syncytial virus infection. Eur J Pediatr 152:125-127

7. Shay DK, Holman RC, Roosevelt GE, Clarke MJ, Anderson LJ 2000 Bronchiolitisassociated mortality and estimates of respiratory syncytial virus-associated deaths among US children, 1979-1997. J Infect Dis 183:16-22

8. Henderson FW, Collier AM, Clyde Jr WA, Denny FW 1979 Respiratory-syncytialvirus infections, reinfections and immunity. A prospective, longitudinal study in young children. N Engl J Med 300:530-534
9. Hall CB, Walsh EE, Long CE, Schnabel KC 1991 Immunity to and frequency of reinfection with respiratory syncytial virus. J Infect Dis 163:693-698

10. Graham BS, Bunton LA, Wright PF, Karzon DT 1991 Role of T lymphocyte subsets in the pathogenesis of primary infection and rechallenge with respiratory syncytial virus in mice. J Clin Invest 88:1026-1033

11. Kapikian AZ, Mitchell RH, Chanock RM, Shvedoff RA, Stewart CE 1969 An epidemiologic study of altered clinical reactivity to respiratory syncytial (RS) virus infection in children previously vaccinated with an inactivated RS virus vaccine. Am J Epidemiol 89:405-421

12. Graham BS 1995 Pathogenesis of respiratory syncytial virus vaccine-augmented pathology. Am J Respir Crit Care Med 152:S63-S66

13. Plotnicky-Gilquin H, Huss T, Aubry JP, Haeuw JF, Beck A, Bonnefoy JY, Nguyen TN, Power UF 1999 Absence of lung immunopathology following respiratory syncytial virus (RSV) challenge in mice immunized with a recombinant RSV G protein fragment. Virology 258:128-140

14. Groothuis JR, King SJ, Hogerman DA, Paradiso PR, Simoes EAF 1998 Safety and immunogenicity of a purified $\mathrm{F}$ protein respiratory syncytial virus (PFP-2) vaccine in seropositive children with bronchopulmonary dysplasia. J Infect Dis 177:467-469

15. Piedra PA, Grace S, Jewell A, Spinelli S, Hogerman DA, Malinoski F, Hiatt PW 1998 Sequential annual administration of purified protein vaccine against respiratory syncytial virus in children with cystic fibrosis. Pediatr Infect Dis J 17:217-224

16. Waris ME, Tsou C, Erdman DD, Day DB, Anderson LJ 1997 Priming with live respiratory syncytial virus (RSV) prevents the enhanced pulmonary inflammatory response seen after RSV challenge in BALB/c mice immunized with formalininactivated RSV. J Virol 71:6935-6939

17. Stein RT, Sherill D, Morgan WJ, Holberg CJ, Halonen M, Taussig LM, Wright AL, Martinez FD 1999 Respiratory syncytial virus in early life and risk of wheeze and allergy by age 13 . Lancet $354: 541-545$

18. Boom R, Sol CJ, Salimans MM, Jansen CL, Wertheim-van Dillen PM, van der Noordaa J 1990 Rapid and simple method for purification of nucleic acids. J Clin Microbiol 28:495-503

19. Nijhuis M, Boucher CA, Schuurman R 1995 Sensitive procedure for the amplification of HIV-1 RNA using a combined reverse-transcription and amplification reaction. Biotechniques 19:178-180, 182

20. Lennette EH, Schmidt NJ 1979 Diagnostic Procedures for Viral, Rickettsial and Chlamydial Infections, 5th Ed. American Public Health Association, Washington, DC, pp 19-21

21. Scott R, Kaul A, Scott M, Chiba Y, Ogra PL 1978 Development of in vitro correlates of cell-mediated immunity to respiratory syncytial virus infection in humans. J Infect Dis 137:810-817

22. Welliver RC, Kaul A, Ogra PL 1979 Cell-mediated immune response to respiratory syncytial virus infection: relationship to the development of reactive airway disease. J Pediatr 94:370-375

23. Hall CB, Geiman JM, Biggar R, Kotok DI, Hogan PM, Douglas Jr GR 1976 Respiratory syncytial virus infections within families. N Engl J Med 294:414-419

24. Fernald GW, Almond JR, Henderson FW 1983 Cellular and humoral immunity in recurrent respiratory syncytial virus infection. Pediatr Res 17:753-758

25. The IMpact-RSV study group 1998 Palivizumab, a humanized respiratory syncytial virus monoclonal antibody, reduces hospitalization from respiratory syncytial virus infection in high-risk infants. Pediatrics 102:531-537

26. The PREVENT Study Group 1997 Reduction of respiratory syncytial virus hospitalization among premature infants and infants with bronchopulmonary dysplasia using respiratory syncytial virus immune globulin prophylaxis. Pediatrics 99:93-99

27. Welliver RC, Tristram DA, Batt K, Sun M, Hogerman DA, Hildreth S 1994 Respiratory syncytial virus-specific cell-mediated immune responses after vaccination with a purified fusion protein subunit vaccine. J Infect Dis 170:425-428

28. Michaels MG, Serdy C, Barbadora K, Green M, Apalsch A, Wald ER 1992 Respiratory syncytial virus: a comparison of diagnostic modalities. Pediatr Infect Dis J 11:613-616

29. Bangham CR McMichael AJ 1986 Specific human cytotoxic T cells recognize B-cell lines persistently infected with respiratory syncytial virus. Proc Natl Acad Sci U S A 83:9183-9187

30. Isaacs D, Bangham CRM, McMichael AJ 1987 Cell-mediated cytotoxic response to respiratory syncytial virus in infants with bronchiolitis. Lancet 2:769-771

31. Kulkarni AB, Connors M, Firestone CY, Morse III HC, Murphy BR 1993 The cytolytic activity of pulmonary CD8 + lymphocytes induced by infection with a vaccinia virus recombinant expressing the M2 protein of respiratory syncytial virus (RSV), correlates with resistance to RSV infection in mice. J Virol 67:1044-1049

32. Biron CA, Nguyen KB, Pien GC, Cousens LP, Salazar-Mather TP 1999 Natural killer cells in antiviral defense: function and regulation by innate cytokines. Annu Rev Immunol 17:189-220

33. Anderson JJ, Serin M, Harrop J, Amin S, Toms GL, Scott R 1989 Natural killer cell response to respiratory syncytial virus in the Balb/c mouse model. Adv Exp Med Biol 257:211-220

34. Hussell T Openshaw PJ 1998 Intracellular IFN-gamma expression in natural killer cells precedes lung CD8 $+\mathrm{T}$ cell recruitment during respiratory syncytial virus infection. J Gen Virol 79(Pt 11):2593-2601

35. Garofalo RP, Mei F, Espejeo R, Ye G, Haeberle H, Baron S, Ogra PL, Reyes VE 1996 Respiratory syncytial virus infection of human respiratory epithelial cells up-regulates class $1 \mathrm{MHC}$ expression through the induction of IFN-beta and IL-1-alpha. J Immunol $157: 2506-2513$

36. Nakayama T, Sonoda S, Urano T, Sasaki K, Maehara N, Makino S 1993 Detection of alpha-interferon in nasopharyngeal secretions and sera in children infected with respiratory syncytial virus. Pediatr Infect Dis J 12:925-929 